\title{
Mallet Toe of the Hallux Treated by Bridging Suture Technique Using Suture Anchors: A Case Report and Literature Review
}

\author{
Akira Ando ${ }^{*}$ (D), Tsutomu Kobayashi ${ }^{1}$, Masashi Koideㄹ, Michimasa Matsuda1, \\ Yoshihiro Hagiwara ${ }^{2}$, Eiji Itoi ${ }^{2}$ \\ ${ }^{1}$ Department of Orthopaedic Surgery, Matsuda Hospital, Sendai, Japan \\ ${ }^{2}$ Department of Orthopaedic Surgery, Tohoku University School of Medicine, Sendai, Japan \\ Email: *andoakir@yahoo.co.jp, riki-kob@outlook.jp, masakoide12@gmail.com,mmatsuda@matsuda-hp.com, \\ hagi@med.tohoku.ac.jp, itoi-eiji@med.tohoku.ac.jp
}

How to cite this paper: Ando, A., Kobayashi, T., Koide, M., Matsuda, M., Hagiwara, Y. and Itoi, E. (2019) Mallet Toe of the Hallux Treated by Bridging Suture Technique Using Suture Anchors: A Case Report and Literature Review. Open Journal of Orthopedics, 9, 123-129.

https://doi.org/10.4236/ojo.2019.95012

Received: April 29, 2019

Accepted: May 24, 2019

Published: May 27, 2019

Copyright $\odot 2019$ by author(s) and Scientific Research Publishing Inc. This work is licensed under the Creative Commons Attribution International License (CC BY 4.0).

http://creativecommons.org/licenses/by/4.0/

\begin{abstract}
An avulsion fracture of the extensor hallucis longus at the distal end of the great toe is called "mallet toe" of the hallux. It is a rare injury and the treatment options are conservative treatment using a splint, percutaneous or open Kirschner wire fixation similar to that in the mallet finger, or suture anchor fixation. We present a case treated by the bridging technique using two suture anchors. A 57-year-old Japanese man injured his left great toe after a fall while walking barefoot on the bed. His great toe was forced into a hyperplantarflexion position. Plain radiography and computed tomography showed a small bone fragment at the base of the dorsal distal phalanx, suggesting an avulsion fracture of the extensor hallucis longus. He was treated by bridging suture technique with two suture anchors. At first, two suture anchors were inserted to the fracture bed of the distal phalanx, and then the bone fragment and extensor hallucis longus tendon were secured with two horizontal mattress sutures. Finally, bridging sutures were performed using the remaining sutures and the sutures used for mattress suturing. He obtained bony union and symmetric range of motion of the interphalangeal joint. This technique allowed us to fix the small bone fragment rigidly and mobilize the interphalangeal joint earlier to preserve the range of motion. It would be a valuable procedure when the bone fragment is small.
\end{abstract}

\section{Keywords}

Mallet Toe, Hallux, Avulsion Fracture, Extensor Hallucis Longus, Suture Anchor 


\section{Introduction}

An avulsion fracture of the extensor hallucis longus at the distal phalanx of the great toe is called "mallet toe" of the hallux [1]. The underlying mechanism of injury is the plantarflexion of distal phalanx to the extended interphalangeal joint similar to that in the mallet injury of the finger [2] [3]. It is a rare injury and its treatment has been reported only in six case reports [1] [4] [5] [6] [7] [8]. These treatments included conservative therapy with a splint to prevent plantarflexion of the hallux [1] [4], Kirschner wire fixation similar to that in bony mallet finger [5] [6] [7], or open reduction and internal fixation with a suture anchor [8]. It is difficult to immobilize the interphalangeal joint in extension with a splint unlike in the mallet injury of the finger [5]. Kirschner wire fixation tends to be less invasive but temporary interphalangeal joint fixation is inevitable, though joint stiffness, osteoarthritis, and infection due to temporary fixation may be rare [5] [6] [7]. One case report described a technique using a suture anchor without transarticular immobilization of the interphalangeal joint [8]. We present a case treated by the suture bridging technique using two suture anchors. This technique allowed us to fix the small bone fragment rigidly and mobilize the interphalangeal joint earlier than the technique with Kirschner wires.

\section{Case Report}

A 57-year-old male banker presented with pain and swelling in his left great toe after a fall, while walking barefoot on the bed. His great toe was forced into a hyperplantarflexion position. On physical examination, he had swollen great toe and a bony prominence at the dorsal aspect of the interphalangeal joint (Figure 1(a)). His hallux was in a flexed position and he could not actively extend the great toe (Figure 1(b)). Plain radiography showed a small bone fragment at the base of the dorsal distal phalanx (Figure 2(a) and Figure 2(b)). The joint was congruent and subluxation was not observed. Computed tomography revealed the size and location of the fragment suggesting an avulsion fracture of the extensor hallucis longus (Figure 2(c) and Figure 2(d)).

Conservative treatment was denied and surgery was performed at two weeks after the injury in the supine position under general anesthesia with a thigh tourniquet. A T-shaped incision over the interphalangeal joint was used for exposure and fracture fixation. After identification of the small avulsed bone fragment and extensor hallucis longus tendon (Figure 3(a)), two $1.9 \mathrm{~mm}$ drill holes were created to the fracture bed and two suture anchors preloaded with two no. 1 nonabsorbable sutures (SUTUREFIX ULTRA, Smith and Nephew Inc., Mansfield, MA) were inserted (Figure 3(b)). The fragment and extensor hallucis longus tendon were secured with two horizontal mattress sutures in the interphalangeal joint extension with care to reduce the fragment properly to the fracture bed. In addition, bridging sutures were performed using the remaining sutures and the sutures used for mattress suturing (Figure 3(c) and Figure 3(d)). 
No complications were observed during surgery and the great toe was immobilized with buddy taping to the second toe to prevent plantarflexion of the interphalangeal joint for two weeks. Heel weight bearing was allowed the day after surgery and passive range of motion exercises were cautiously initiated once the wound was completely healed. At four weeks, partial toe weight bearing was allowed and full toe weight bearing was initiated at two months after the surgery. Three months after the surgery, bony union was confirmed both with plain radiography and computed tomography (Figure 4), and symmetric range of motion of the interphalangeal joint was obtained. At one year, the patient did not complain of any pain during walking and running. Written informed consent was obtained from the patient for publication of this case report and accompanying images.
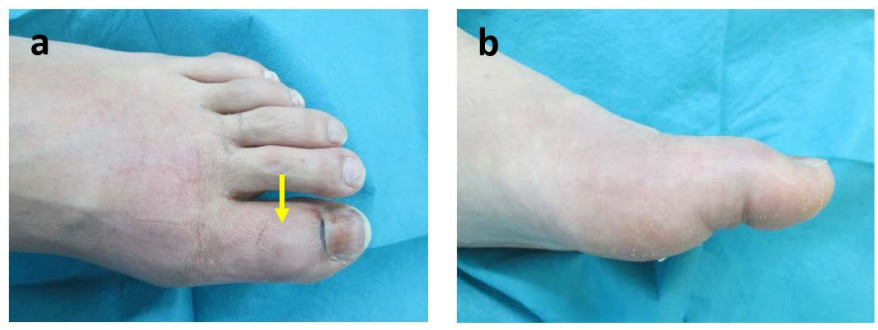

Figure 1. Macroscopic findings of the great toe. A bony prominence (arrow) at the dorsal aspect of the interphalangeal joint was observed (a), the great toe was in the flexed position active extension was not possible (b).
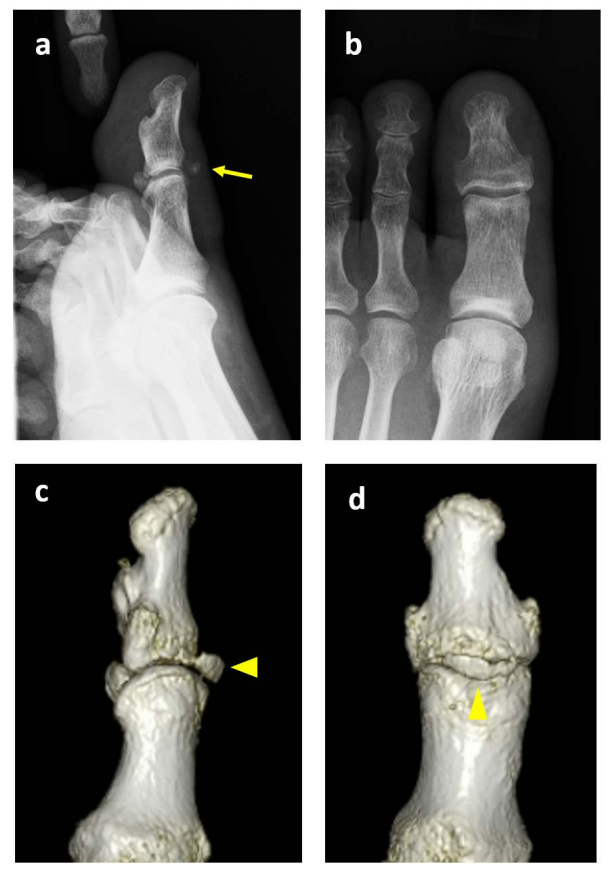

Figure 2. Plain radiographs and three-dimensional computed tomography of the great toe. Lateral (a) and anteroposterior (b) radiographs revealed a small bone fragment (arrow) at the dorsal base of the distal phalanx. Computed tomography of the lateral (c) and dorsal (d) aspects of the great toe indicated a small avulsion fracture of the extensor hallucis longus (arrowheads). 

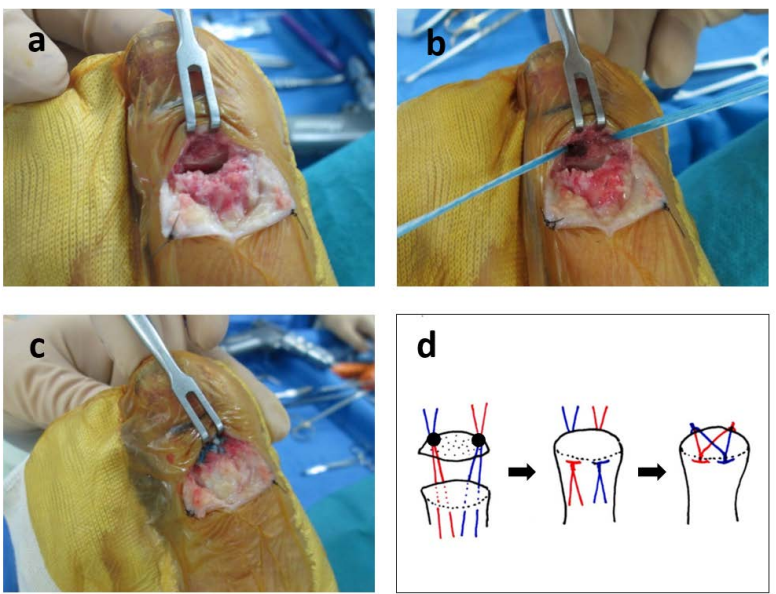

Figure 3. Surgical technique applied to the great toe. Intraoperative photographs after exposure of the fracture site (a), insertion of the two suture anchors (b) and fixation of the bone fragment with the bridging technique (c). Schematic illustration of the surgery $(\mathrm{d})$.
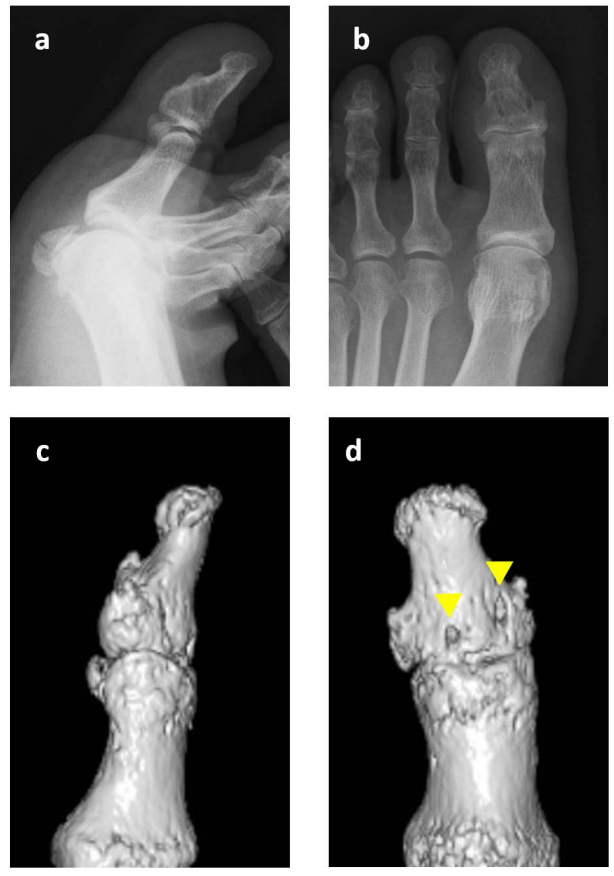

Figure 4. Lateral (a) and anteroposterior (b) plain radiographs and lateral (c) and dorsal (d) aspect of the computed tomography at three months after the surgery. Bone union was achieved and two drill holes were observed (arrowheads).

\section{Discussions}

Mallet toe of the hallux is a rare entity and has been named as "mallet toe", because its injury mechanism is similar to that of "mallet finger". All previous reports have described that the injury occurs as a result of hyperplantarflexion or a stubbing mechanism such as falling down on the tip of the great toe like in our case and kicking an object in an extended position of the interphalangeal joint (Table 1) [1] [4] [5] [6] [7] [8]. 
Table 1. Summary of previously reported and present cases of mallet toe of the hallux.

\begin{tabular}{|c|c|c|c|c|c|}
\hline & $\begin{array}{l}\text { Age } \\
\text { (Sex) }\end{array}$ & $\begin{array}{l}\text { Mechanism of } \\
\text { injury }\end{array}$ & $\begin{array}{l}\text { Size of bony } \\
\text { fragment }\end{array}$ & Treatment & Outcomes \\
\hline Rapoff & $36(\mathrm{M})$ & $\begin{array}{l}\text { Caught on the } \\
\text { edge of the step }\end{array}$ & $45 \%$ of JS & $\begin{array}{l}\text { Rigid-soled sandal for } \\
10 \text { weeks to prevent } \\
\text { plantarflexion }\end{array}$ & $\begin{array}{l}\text { Returned at } 16 \\
\text { weeks and } 10 \% \\
\text { ROM restriction }\end{array}$ \\
\hline Hennessy & $45(\mathrm{M})$ & $\begin{array}{l}\text { Fall during } \\
\text { descending } \\
\text { stairs }\end{array}$ & Small & $\begin{array}{l}\text { Dorsal thermoplastic } \\
\text { extension splint for } 8 \\
\text { weeks }\end{array}$ & $\begin{array}{l}50 \% \text { ROM restriction } \\
\text { and minor flexion } \\
\text { deformity }\end{array}$ \\
\hline Nakamura & $51(\mathrm{M})$ & $\begin{array}{l}\text { Stubbed on the } \\
\text { threshold of } \\
\text { sliding door }\end{array}$ & Small & $\begin{array}{l}\text { IP joint fixation with a } \\
\text { K-wire for } 5 \text { weeks after } \\
\text { failed conservative } \\
\text { treatment }\end{array}$ & $\begin{array}{l}\text { Slight limitation in } \\
\text { flexion at } 1 \text { year }\end{array}$ \\
\hline Wada & $49(\mathrm{M})$ & $\begin{array}{l}\text { Caught on a } \\
\text { carpet barefoot }\end{array}$ & $\begin{array}{l}\text { More than } \\
50 \% \text { of JS }\end{array}$ & $\begin{array}{l}\text { Extension block method } \\
\text { with two K-wire for } 4 \\
\text { weeks }\end{array}$ & $\begin{array}{l}\text { Returned at } 8 \text { weeks } \\
\text { and no description } \\
\text { about ROM }\end{array}$ \\
\hline Martin & $16(\mathrm{M})$ & $\begin{array}{l}\text { Kicking a ball } \\
\text { barefoot }\end{array}$ & $40 \%$ of JS & $\begin{array}{l}\text { Open reduction and } \\
\text { fixation with two K-wire } \\
\text { and temporal IP joint } \\
\text { fixation for } 5 \text { weeks after } \\
\text { failed closed reduction }\end{array}$ & $\begin{array}{l}\text { Full activity except } \\
\text { for sports at } 3.5 \\
\text { months and } \\
\text { symmetric ROM }\end{array}$ \\
\hline Hong & $\begin{array}{l}\text { 1) } 39(\mathrm{~F}) \\
\text { 2) } 46(\mathrm{M})\end{array}$ & $\begin{array}{l}\text { 1) Fall at the } \\
\text { slope } \\
\text { 2) Kicking an } \\
\text { opponent }\end{array}$ & $\begin{array}{l}\text { 1) } 40 \% \text { of JS } \\
\text { 2) } 30 \% \text { of JS }\end{array}$ & $\begin{array}{l}\text { One suture anchor } \\
\text { fixation with two drill } \\
\text { holes into the fragment }\end{array}$ & $\begin{array}{l}\text { Returned at } 2 \text { and } 3 \\
\text { months and no and } \\
\text { slight ROM } \\
\text { limitation }\end{array}$ \\
\hline Ando & $57(\mathrm{M})$ & $\begin{array}{l}\text { Fall from the } \\
\text { bed barefoot }\end{array}$ & Small & $\begin{array}{l}\text { Two suture anchor } \\
\text { fixation with suture } \\
\text { bridging technique }\end{array}$ & $\begin{array}{l}\text { Returned at } 2 \\
\text { months and no ROM } \\
\text { limitation }\end{array}$ \\
\hline
\end{tabular}

M, male; F, female; JS, joint surface; K-wire, Kirschner wire; IP, interphalangeal; ROM, range of motion.

Treatment options for the injury are conservative treatment [1] [4], percutaneous or open Kirschner wire fixation [5] [6] [7], or suture anchor fixation [8]. Rapoff et al. reported a case treated with a rigid soled sandal for ten weeks [4], and Hennesy et al. reported using a dorsal thermoplastic extension splint for eight weeks [1]. Although these studies reported acceptable results, restriction in range of motion, flexion deformity, and extensor lag of the hallux persisted after these treatments [1] [4].

Surgical treatment with Kirschner wires was described by three authors [5] [6] [7]. Nakamura reported a case treated with temporary interphalangeal joint fixation using a Kirschner wire after failed conservative treatment due to continued swelling and difficulty in maintaining the fragment in a reduced position [5]. Wada et al. reported a case treated with the extension block method using two Kirschner wires usually applied for the mallet finger [6]. Martin et al. reported a case treated with open reduction and fixation using two Kirschner wires and temporary interphalangeal joint fixation after failed percutaneous treatment [7]. These three case reports showed good clinical results, but the temporary transarticular fixation of the interphalangeal joint with a Kirschner wire and care of the surgical site for a few weeks is inevitable [5] [6] [7]. 
Hong et al. reported two cases treated with a suture anchor for reattaching the avulsed fragment without transarticular immobilization of the interphalangeal joint [8]. They reported that a suture anchor was inserted into the fracture bed of the distal phalanx and two drill holes were made into the avulsed fragment. Thereafter, the fragment was secured with sutures [8]. This technique is applicable when the avulsed fragment is large enough for two drill holes. However, it is difficult when the fragment is small for drilling holes directly into it, like in our case. The reported size of the fragment was divided into two groups, 30\% to 50\% of the joint surface [4] [6] [7] [8] or too small to measure as in our case [1] [5]. In the present case, two suture anchors were inserted into the fracture bed of the distal phalanx, and two mattress sutures were made just proximal to the avulsed fragment in the interphalangeal joint extension. Finally, the fixation was reinforced with bridging sutures. This technique provided sufficient fixation of the avulsed fragment to allow early postoperative mobilization of the interphalangeal joint and good clinical results were obtained without limitation of the interphalangeal joint range of motion. This technique can be a valuable procedure when the bone fragment is small.

\section{Conclusion}

Bridging suture technique with two suture anchors allowed us to fix the small bone fragment rigidly and mobilize the interphalangeal joint earlier to preserve the range of motion.

\section{Conflicts of Interest}

The authors declare no conflicts of interest regarding the publication of this paper.

\section{References}

[1] Hennessy, M.S. and Saxby, T.S. (2001) Traumatic 'Mallet Toe' of the Hallux: A Case Report. Foot and Ankle International, 22, 977-978. https://doi.org/10.1177/107110070102201209

[2] Bendre, A.A., Hartigan, B.J. and Kalainov, D.M. (2015) Mallet Finger. The Journal of the American Academy of Orthopaedic Surgeons, 13, 336-344. https://doi.org/10.5435/00124635-200509000-00007

[3] Leinberry, C. (2009) Mallet Finger Injuries. The Journal of Hand Surgery, 34, 1715-1717. https://doi.org/10.1016/j.jhsa.2009.06.018

[4] Rapoff, A.J. and Heiner, J.P. (1999) Avulsion Fracture of the Great Toe: A Case Report. Foot and Ankle International, 20, 337-339. https://doi.org/10.1177/107110079902000514

[5] Nakamura, S. (2007) Temporary Kirschner Wire Fixation for a Mallet Toe of the Hallux. Journal of Orthopaedic Science, 12, 190-192. https://doi.org/10.1007/s00776-006-1106-x

[6] Wada, K. and Yui, M. (2011) Surgical Treatment of Mallet Toe of the Hallux with Extension Block Method: A Case Report. Foot and Ankle International, 32, 1086-1088. https://doi.org/10.3113/FAI.2011.1086 
[7] Martin, E.A., Barske, H.L. and DiGiovanni, B.F. (2013) Open Surgical Treatment of an Acute, Unstable Bony Mallet Injury of the Hallux. Foot and Ankle International, 34, 295-298. https://doi.org/10.1177/1071100712465850

[8] Hong, C.C. and Tan, K.J. (2013) Suture Anchor Fixation of Unstable Bony Mallet Injuries of the Hallux. Foot and Ankle International, 34, 1737-1741.

https://doi.org/10.1177/1071100713499906 